\title{
Article \\ The Needed Features of Connected and Automated Vehicles to Prevent Passenger Car Crashes Caused by Driving Errors
}

\author{
Roni Utriainen*(D) and Markus Pöllänen \\ Transport Research Centre Verne, Tampere University, P.O. Box 600, FI-33014 Tampere, Finland; \\ markus.pollanen@tuni.fi \\ * Correspondence: roni.utriainen@tuni.fi
}

check for updates

Citation: Utriainen, R.; Pöllänen, M. The Needed Features of Connected and Automated Vehicles to Prevent Passenger Car Crashes Caused by Driving Errors. Future Transp. 2021, 1, 370-386. https://doi.org/10.3390/ futuretransp1020021

Academic Editor: Javier Faulin

Received: 1 June 2021

Accepted: 30 August 2021

Published: 3 September 2021

Publisher's Note: MDPI stays neutral with regard to jurisdictional claims in published maps and institutional affiliations.

Copyright: (c) 2021 by the authors. Licensee MDPI, Basel, Switzerland. This article is an open access article distributed under the terms and conditions of the Creative Commons Attribution (CC BY) license (https:// creativecommons.org/licenses/by/ $4.0 /)$.

\begin{abstract}
Connected and automated vehicles (CAVs) can enhance traffic safety considerably. However, as CAVs are currently under development, the safety impact cannot be assessed directly. In this study, driver-managed passenger car crashes with fatalities in Finland were investigated qualitatively to evaluate the needed features of the CAVs to avoid these crashes. The focus was on single-car crashes and collisions between passenger cars, in which the immediate risk factor was a driving error $(n=48)$. Most of the analysed crashes (33 of 48) were due to loss of control with typically adverse weather or road conditions. To avoid these crashes, a CAV should be able to adjust its speed according to the conditions. In 13 of 48 crashes, the car was under control prior to the crash. A reliable capability to recognize other road users is an important CAV feature, because observational errors were common in these cases. In addition, communication between the vehicles could assist in avoiding intersection crashes and crashes caused by a sudden change in weather conditions. This study increases knowledge on crashes related to driving errors and the needed features of CAVs to avoid these crashes. In particular, CAVs' feature to adjust the speed is important, because cases of loss of control in adverse weather or road conditions were typical events.
\end{abstract}

Keywords: CAV; connected and automated vehicle; operational capability; safety impacts

\section{Introduction}

Growing passenger and freight transport volumes make it more difficult to achieve the sustainable development goals [1,2]. In the future, one solution will include vehicle automation and new mobility services (e.g., shared mobility), which aim to make road traffic more efficient and sustainable while providing individuals seamless journeys without owning a car $[3,4]$. In addition to these potential impacts of vehicle automation, safety promotion is one of the most important predicted impacts of automation in road traffic [5]. Companies (e.g., Waymo [6]), researchers (e.g., Fagnant and Kockelman [7]), and authorities (e.g., the U.S. Department of Transportation [8]) have stated that highly automated or connected and automated vehicles (CAVs) will enhance road traffic safety. These vehicles represent SAE [9] level four or five. The C in the CAV; i.e., connectedness, refers to technologies enabling communication between all contributing agents or stakeholders, including pedestrians, authorities, vehicles, and infrastructure [10], and can be implemented, for example, in intersection control and collision-free navigation [11]. The different stakeholders assume that CAVs will reduce the number of crashes. The thought has been that most crashes could be avoided by CAVs, as about $95 \%$ of the current crashes are caused by human errors $[12,13]$. However, data-based evidence on CAVs' potential safety impacts is deficient, because there is no data on advanced CAV operation in different traffic environments and conditions [14]. We especially lack information on the vehicles' ability to operate in diverse conditions [15]. In addition, the claims that human errors caused the crashes, and that these crashes could be avoided by implementing CAVs, have been criticised [16].

Speeding, intoxicants, the driver's health, etc. are typical driver-related background risk factors in fatal crashes [17]. When human drivers are replaced by CAVs, many crashes 
are theoretically avoidable, assuming the CAVs are able to operate at least as safely as human drivers, and that the driver-related risks are removed when CAVs manage the driving task. There are, however, crashes in which the immediate risk factor is a driving error, but there are not obvious driver-related background risk factors present. These crashes may be challenging to avoid by CAVs, and hence, they should be studied from the perspective of CAV operation to support technology development and CAVs' operational capabilities; e.g., in different weather conditions and complex traffic environments. In this study, we focused on CAVs' possibilities and needed operational requirements to avoid crashes caused by driving errors.

We analysed data on Finnish in-depth investigated crashes to qualitatively explore the actual crashes in which a driving error was the immediate risk factor, and what kind of actions would have been needed to avoid these crashes if CAVs were involved in a similar scene instead of driver-managed passenger cars. The focus was solely on crashes with driving errors, because the CAVs should be able to avoid the identifiable driver-related risks (e.g., speeding and intoxicants) when operating in fully autonomous mode, and thus also avoid the crashes. We considered that focusing on these crashes would provide the most relevant findings from the perspective of CAVs' safety potential, as the needed features or actions of the CAV were not apparent in these crashes. By analysing real-world crashes, we sought to identify the observations and actions that CAVs should take to avoid them. The research questions were:

1. What are the key characteristics of the fatal passenger car crashes in which a driving error was the immediate risk factor?

2. What kind of operational capabilities should the CAVs have, and what actions should they take to avoid the crashes caused by driving errors?

In the next section, previous studies on CAVs' safety impacts are presented. The methods and data of this study are described in Section 3, and the results in Section 4. Sections 5 and 6 present a discussion and our conclusions.

\section{CAVs' Safety Impact}

One of the most cited studies on the safety impacts of CAVs, by Fagnant and Kockelman [7], states that crashes could be reduced by $90 \%$ in the United States with a CAV market penetration rate of $90 \%$ due to the vehicles' impact on removing human errors. There is a need for specific analyses related to the removal of human errors in order to evaluate how CAVs should operate in different traffic situations and safety-critical situations. Related to the claim by Fagnant and Kockelman [7], it is worth noting that CAVs' market penetration is not expected to reach $90 \%$ for a long time [18]. Removal of all human errors could be possible in an ideal world, but at the current stage of CAV development, human errors could be replaced by system errors. However, the safety potential of CAVs is built on the assumption that the system errors would not be as common as human errors in the current driver-managed vehicles, but their error-free operation is not easy to guarantee. For instance, a deficient safety-management system was reported to be one of the reasons leading to a fatal crash between an Uber car, which was operated by a developmental automated driving system, and a pedestrian in the United States in 2018 [19]. In addition, several Tesla crashes with partial automation have been reported [20], which highlighted the challenges of automated driving and the problematic human-machine interface at the current stage of development.

CAVs may not have a great impact on fatal crashes in the near future, because the majority of the fatal crashes are situated on rural roads excluding motorways in the EU [21]. These roads are probably relatively challenging traffic environments for new technology. In the longer term, connected vehicle technologies between vehicles (V2V) or between vehicles and infrastructure (V2I) could support CAVs operating in all traffic environments or conditions [14]. For instance, V2V and V2I technologies could warn about approaching vehicles at intersections or changing weather conditions [22]. Connectivity has been assessed to be a notable factor in ensuring automated vehicle safety [23]. 
Recent studies have typically simulated and modelled CAVs' potential operation to evaluate the potential safety impacts. Several studies have focused on some specific traffic environment or intersections, such as roundabouts [24,25], other intersection types [14,25], motorways and freeways [26,27], or other urban and rural road areas [28-30]. Several of these studies evaluated the safety impacts with different CAV market penetration rates, which enabled studying the potential safety impacts of mixed traffic consisting of both $\mathrm{CAVs}$ and driver-managed vehicles. It should be noted that most of the previous studies evaluated changes in the amount of conflicts instead of crashes. Some studies (e.g., [31-33]) evaluated the safety potential of a wide set of driver-assistance systems, which link with the operational capabilities of a CAV at some level, albeit the driver is responsible for the driving task. These studies are typically based on applying evaluation of the average safety potential of the systems, which have been identified in previous research.

According to simulation studies and studies combining the impacts of several driverassistance systems, 19\% [29] to 100\% [25] of the light vehicle crashes or conflicts in specific traffic environments could be avoided by CAVs with a penetration rate of $90-100 \%$. In the study by Tafidis et al. [29], in which rear-end, crossing, and lane-change conflicts were studied in an urban area, conflict-reduction potential of CAVs was lower compared to that found in other studies. The lower safety potential may indicate that urban areas are more challenging environments for CAV operation. However, Morando et al. [14] and Virdi et al. [25] found that conflicts could potentially be reduced by $64-98 \%$ at roundabouts and $48-65 \%$ at signalized intersections with a market penetration rate of $90 \%$ or more. On motorways and freeways, a rear-end risk or the number of conflicts could theoretically be decreased by $90-95 \%$ [26,27], which highlighted the high safety potential in more straightforward traffic environments. Overall, the conflict or crash reduction potential ranged from $33 \%$ to $46 \%$ for several driver-assistance systems [31], and was up to $100 \%$ when the reduction potential of CAVs' conflicts in priority intersections was considered [25]. While the previous studies suggest promising results on CAVs' safety impact, the range of the estimated crash or conflict avoidance potential is wide, which is probably due to the variety of traffic situations and lack of data on the actual operation of CAVs. In addition, the impact of a human operator on safety is still unsure; i.e., if the operator is not ready to answer a take-over request [34].

Previous studies involving potential safety impacts have mostly simulated and modelled a CAV's hypothetical operation. Simulation and modelling enable studying the safety impacts in a specific research area (e.g., an intersection or a small city area), including the evaluation of future crashes and conflicts. However, the results of the simulation studies depended highly on the defined CAV parameters [29]. Currently, CAVs' operating procedure is not known precisely enough, as data are not available on advanced CAVs actual operation [28].

In the simulation studies, CAVs may have been determined to operate more cautiously than manually driven vehicles. For instance, the CAVs have been modelled to accelerate more slowly and to be more willing to wait in a queue rather than to aggressively merge into another lane [35]. The described behaviour may be needed to ensure CAVs' safe operation. To support the development of CAVs and evaluation of the results on their safety potential, this study discusses the different features and operational capabilities of the CAV that are needed to prevent crashes.

\section{Materials and Methods}

In this study, we analysed CAVs' potential to prevent passenger car crashes in which driving error was the immediate risk factor. For study purposes, we received in-depth investigated crash data from the Finnish Crash Data Institute. The data included crash descriptions and descriptive factors on the crashes based on the investigations by multidisciplinary crash investigation teams. The investigation procedures have a long history in Finland, and since 2001, in-depth investigations of fatal road crashes have been mandated by law [36]. The data included all fatal passenger car crashes $(n=249)$ that had occurred in 
Finland in 2014-2016. Crashes in which a motor vehicle other than a passenger car was involved, or that involved a cyclist or pedestrian, were excluded from the analysis. Thus, the analysed data included single-car crashes and collisions between passenger cars.

As we focused on the crashes in which the immediate risk factor was a driving error, we excluded the crashes in which the driver's physical condition or health was identified as influencing the crash outcome in the analysis. The analysis regarding the driver's physical condition in the crashes was made by crash investigation teams based, for example, on medical data (attack of illness) and the overall crash assessment, including interviews of the witnesses, persons involved, and their family members (in intentionally caused crashes).

Out of the original data set $(n=249)$, crashes due to a driver's attack of illness $(n=63)$, intentionally caused crashes $(n=19)$, and crashes due to decreased alertness $(n=18)$ were excluded (see Figure 1), because these driver-related risks can assumedly be removed by CAVs. Additionally, as the scope was the crashes in which the driver had obeyed the law, we excluded the crashes in which the driver had been speeding excessively (more than $20 \mathrm{~km} / \mathrm{h}$ over the speed limit) $(\mathrm{n}=93)$ or drove under the influence of alcohol or drugs $(\mathrm{n}=81)$, because CAVs would likely operate differently in these cases, and would likely enable avoiding the crash. Our criterion related to excessive vehicle speed was comparable to the Finnish study by Kelkka and Toivonen [37], in which it was defined that crashes occur in typical or normal traffic conditions, when the speed limit is not exceeded by more than $20 \mathrm{~km} / \mathrm{h}$ in rural roads. The limit for blood alcohol content is $0.05 \%$ in Finland, and we used this as the threshold value for driving under the influence of alcohol. For driving under the influence of drugs, we used the value given by the investigation team (yes/no). The final data consisted of 48 fatal crashes including 20 head-on, 18 single-car, 8 intersection and 2 rear-end crashes, which were analysed separately, as these differ in their natures.

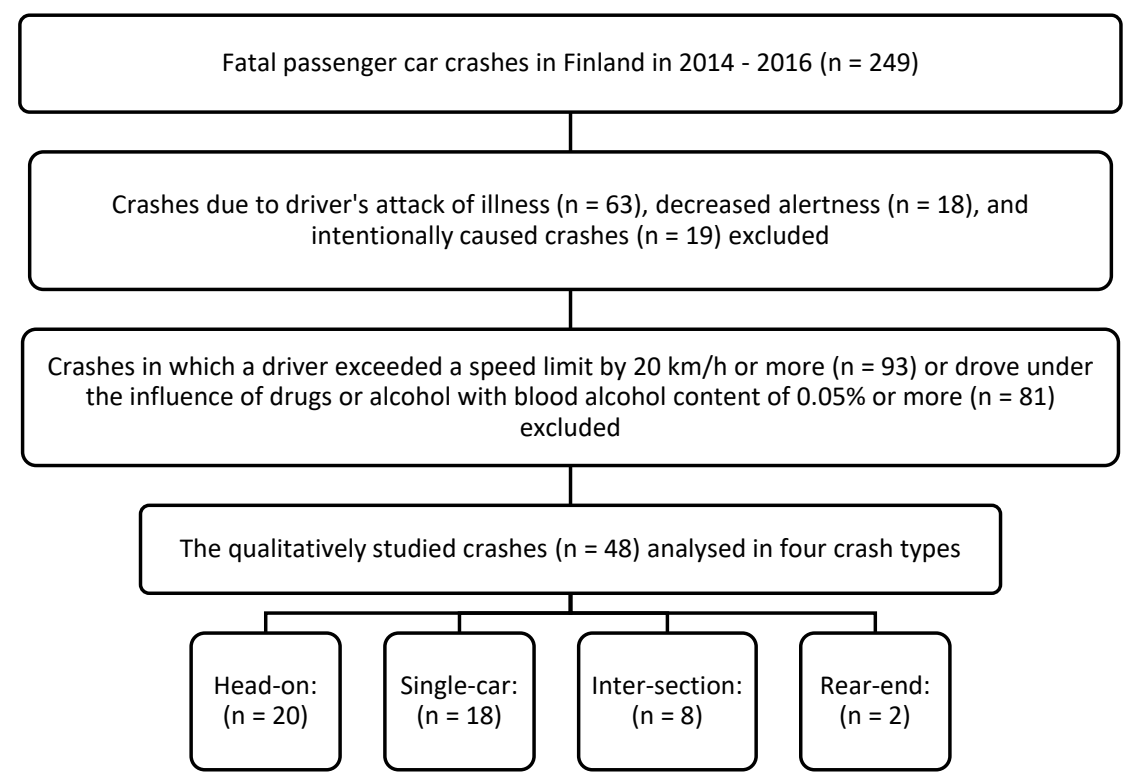

Figure 1. The management of the research data and the data in the four analysed crash types.

The analysis was based on qualitative evaluation of the available in-depth investigated crash data and considered each crash case individually; i.e., case-by-case. When analysing the crash data, the events prior to the crash were evaluated, as well as the immediate risk factor, which described the cause of the crash. The immediate risk factor is the factor that actively influenced the occurrence of the crash (e.g., a steering error). The immediate risk factor is dissimilar from the background risk factors (e.g., driving under the influence of alcohol), which enable the occurrence of the immediate risk factor. Of the variables in the data, "pre-crash event" described the change in the normal flow of the traffic, which enabled the occurrence of the crash (e.g., the vehicle's movement into the oncoming lane). In addition, variables of the car's motion in the pre-crash event (e.g., the vehicle 
curved left) and the control of the car in the pre-crash event (e.g., loss of control without braking) were considered. The variables and framework of the study are presented in Figure 2. Characteristics of the crashes and variables used in the analysis are presented in Appendix A, and the different crash types in Appendix B.

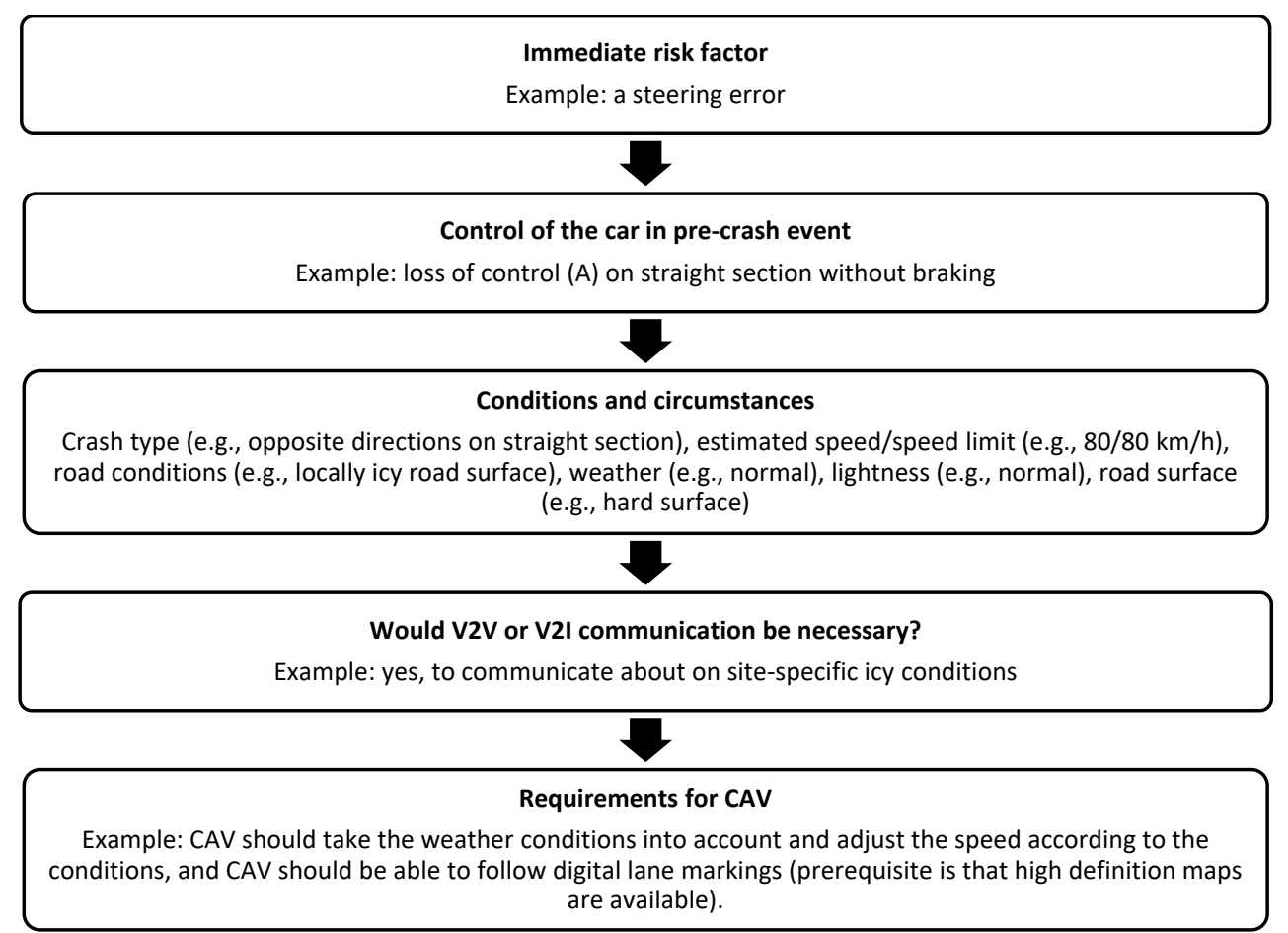

Figure 2. The variables considered in the analysis of crash data and crash avoidance, and characteristics of an example crash.

With the crash data, we were able to investigate the occurrence of the crash, and what features and actions should be considered in the capabilities and operation of a CAV in order to prevent the crash. In addition, we investigated the potential benefits of connected vehicle technologies in the avoidance of crashes. In the analysis, we evaluated whether information on changes in weather conditions, road-surface slipperiness, approaching vehicles at intersections, or oncoming traffic in the same lane in case of an overtaking would be necessary for crash avoidance.

Figure 3 presents the different immediate risk factors and the states of a car's control in the pre-crash events, which had been identified by the crash investigation teams in the analysed crashes. Altogether, 11 different immediate risk factors were recognized, as well as three states of the car's control, which are marked as A (loss of control), B (under control), and C (not steered). In addition, the evaluation of the actions a CAV should take to avoid the crashes are presented. For instance, loss of car's control (A) may have been caused by several immediate risk factors, such as a wrong driving path or a steering error. While all risk factors in the analysed crashes related to driver errors, diverse actions would be needed to prevent these crashes by a CAV, because the driving errors have been different. For instance, reducing speed could be a typical measure to prevent loss of a car's control, but it is not the only measure that is needed. The following actions or features of the $\mathrm{CAV}$ were recognized as necessary to prevent the analysed crashes, including different combinations of immediate risk factors, state of the car's control, and other circumstances:

1. CAV operates without steering or judgment errors.

2. CAV manages to keep the car on the right lane.

3. CAV takes the weather conditions into account and adjusts the speed (to a safe speed) according to the weather conditions in each road section.

4. CAV overtakes only when overtaking can be conducted safely. 
5. CAV is always $100 \%$ operational.

6. At intersections, $\mathrm{CAV}$ recognises the approaching car and assesses the right and safe moment to go straight or turn.

7. CAV operates without observation errors for the other cars' movements.

8. CAV manages to follow digital lane markings (the availability of high definition maps as a prerequisite).

\begin{tabular}{|c|c|c|c|c|c|c|c|c|}
\hline $\begin{array}{c}\text { Immediate } \\
\text { error } \\
\text { unclear: } \\
\mathrm{A}(\mathrm{n}=1)\end{array}$ & $\begin{array}{c}\text { Wrong } \\
\text { judgment on } \\
\text { own } \\
\text { possibilities } \\
\text { to proceed: } \\
\text { A }(\mathrm{n}=7)\end{array}$ & $\begin{array}{c}\text { Wrong } \\
\text { driving } \\
\text { path: } \\
\mathrm{A}(\mathrm{n}=2), \\
\mathrm{B}(\mathrm{n}=2) \text { and } \\
\text { unknown } \\
(\mathrm{n}=1)\end{array}$ & $\begin{array}{c}\text { Incorrect } \\
\text { observation: } \\
\text { A }(\mathrm{n}=2) \text { and } \\
\text { B }(\mathrm{n}=4)\end{array}$ & $\begin{array}{c}\text { Other } \\
\text { driver- } \\
\text { related act: } \\
A(n=1) \\
\text { and } B(n=1)\end{array}$ & $\begin{array}{l}\text { Other } \\
\text { anticipation- } \\
\text { related act: } \\
\mathrm{A}(\mathrm{n}=1)\end{array}$ & $\begin{array}{c}\text { Steering } \\
\text { error: } \\
\text { A }(n=19) \\
\text { and } \\
C(n=1)\end{array}$ & $\begin{array}{l}\text { Overtaking } \\
\text { or } \\
\text { approaching } \\
\text { an } \\
\text { intersection } \\
\text { without } \\
\text { proper } \\
\text { anticipation } \\
\text { and } \\
\text { confirming: } \\
\mathrm{B}(\mathrm{n}=2)\end{array}$ & $\begin{array}{c}\text { Driver did } \\
\text { not } \\
\text { recognise } \\
\text { the other } \\
\text { car: } \mathrm{B}(\mathrm{n}=4)\end{array}$ \\
\hline
\end{tabular}

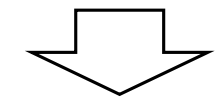

\begin{tabular}{|c|l|l|}
\hline \multicolumn{3}{|c|}{ State of car's control in pre-crash event } \\
\hline $\begin{array}{c}\text { Loss of control (A) } \\
\text {-The car drifted out of the lane due to loss of control }\end{array}$ & $\begin{array}{l}\text { Under control (B) } \\
\text {-The car was on the wrong lane or location } \\
\text { in crashes, in which the car was under } \\
\text { driver's control }\end{array}$ & $\begin{array}{l}\text { Not steered (C) } \\
\text {-The car drifted out of the lane, because it } \\
\text { not } \\
\text { driver's control but the car was under }\end{array}$ \\
\hline
\end{tabular}

\begin{tabular}{|c|c|c|}
\hline \multicolumn{3}{|c|}{$\begin{array}{l}\text { Evaluation on actions CAV should take specific to each state of car's control case (below) and if lane markings are not fully visible due to } \\
\text { e.g., snow-covered road surface or gravel paved road, digital lane markings are needed to recognize the lane (action } 8 \text { ) }\end{array}$} \\
\hline $\begin{array}{l}\text {-Under normal conditions, CAV obeys speed limit } \\
\text { and operates error-free }(1,2) \\
\text {-On slippery road surface or in poor visibility, CAV } \\
\text { takes the conditions into account and adjusts the } \\
\text { speed according to the conditions (3) } \\
\text {-To prevent loss of control after overtaking, CAV } \\
\text { ensures overtaking is safe within the speed limit (4) }\end{array}$ & $\begin{array}{l}\text {-CAV acknowledges the location of the } \\
\text { lane and keeps the car inside the right lane } \\
\text { (2) } \\
\text {-CAV makes correct observations on } \\
\text { other car's movement and follows the } \\
\text { leading car all the time to avoid e.g., rear- } \\
\text { end crashes (7) } \\
\text {-In overtaking situations, CAV ensures } \\
\text { that overtaking is safe (4) } \\
\text {-At intersections, CAV recognizes the cars } \\
\text { approaching from different directions } \\
\text { and obeys the obligation to yield (6) }\end{array}$ & -CAV is always $100 \%$ operational (5) \\
\hline
\end{tabular}

Figure 3. The linkage between the immediate risk factors and the state of a car's control in a pre-crash event, and a description of potentially needed features and actions to prevent crashes by CAVs with different combinations of the immediate risk factors and pre-crash events.

An analysis related to the evaluation of different crash types is depicted next. In head-on and single-car crashes, the car drifted into the lane of opposite running direction (head-on) or off the road (single-car). The control of the car was observed prior to the lane departure. In head-on and single-car crashes, it is essential to identify the risk factors leading to the lane departure, and how this could be avoided by a CAV.

In intersection crashes, the at-fault driver (e.g., the driver with an obligation to yield) did not recognize another involved car at all or early enough to avoid the crash. We assessed the possibilities of the at-fault party (CAV in the analysis) to avoid the crash, because the possibility of the other involved party to prevent the crash was assumed as 
unlikely due to clearly higher speeds compared to the at-fault party in the studied crashes. It was assumed that a CAV was able to recognize another involved $\mathrm{CAV}$, when turning at the intersection began or when the CAV was about to cross the intersecting lane, in the case of going straight through the intersection. In reality, the CAV may have recognized the other car approaching the intersection earlier, but this could not be confirmed using the available crash data. As depicted in Figure 4, we conducted a time-to-collision (TTC) analysis (1), in which TTC is the time distance between the trigger point and the collision point. TTC represents the distance from the at-fault car's perspective. The trigger point is the location at which the at-fault car began to turn at the intersection, or entered the intersection in the case of going straight through.

$$
\mathrm{TTC}=\frac{X_{f}}{V_{f}}
$$

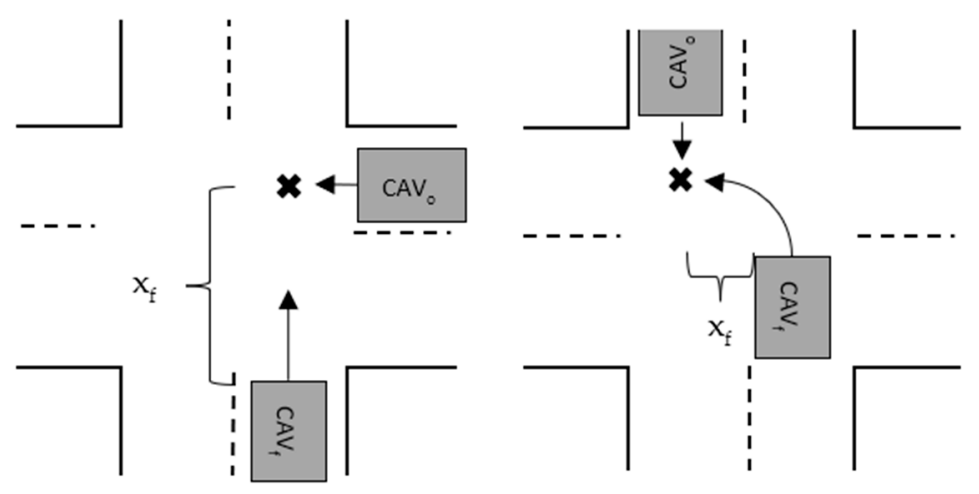

Figure 4. Visualisation of the distance to the collision point $\left(X_{f}\right)$ from the at-fault car's point of view used in the TTC analysis when the at-fault car was going straight through the intersection (left figure) or turning left (right figure).

The distance $\left(X_{f}\right)$ is from the point the at-fault car (e.g., with the obligation to yield at the intersection) began to turn or entered the intersection to the point at which the collision occurred with the other involved vehicle (Figure 4 ). $V_{f}$ is the speed of the at-fault car prior to the collision.

In rear-end crashes, the driver of the rear-ending car did not recognize the rear-ended car, or the driver had lost control of the car. In these cases, it was found that the CAV would have been able to recognize the danger earlier, which would have allowed more time to avoid the collision. We also assessed the actions needed to prevent loss of control of the car, which led to the collision. In the analysis, we also used the variable of time distance (e.g., when the driver recognized the danger). We assumed that the CAV's sensor could recognize the danger at the same moment that the driver had done so. By investigating the immediate risk factor, it was possible to evaluate whether the CAV may have been able to recognize the danger earlier than the driver. We evaluated the time distance of the recognising moment that could have been possible if a driver-managed car had been replaced by a CAV.

\section{Results}

\subsection{Head-on Crashes}

Head-on crashes were typically caused by a steering error $(n=11)$ or a wrong driving path $(n=4)$. Regarding the pre-crash events, loss of control $(A, n=15)$ was the most common (Table 1). 
Table 1. Characteristics of the 20 studied head-on crashes.

\begin{tabular}{|c|c|c|c|c|}
\hline $\begin{array}{c}\text { Immediate Risk Factor (Code } \\
\text { of the Crash Type in } \\
\text { Parentheses) }\end{array}$ & $\begin{array}{c}\text { Control of the Car in the } \\
\text { Pre-Crash Event }\end{array}$ & $\begin{array}{c}\text { Estimated Speed/ } \\
\text { Speed Limit } \\
(\mathrm{km} / \mathrm{h})\end{array}$ & $\begin{array}{l}\text { Requirements } \\
\text { for CAV }\end{array}$ & $\begin{array}{c}\text { V2V or V2I } \\
\text { Communication } \\
\text { Need }\end{array}$ \\
\hline $\begin{array}{l}\text { Incorrect observation on car's } \\
\text { location on roadway, normal } \\
\text { conditions (20) }\end{array}$ & $\begin{array}{l}\text { Loss of control (A) on curve } \\
\text { with braking }\end{array}$ & NA/80 & (2) & No \\
\hline $\begin{array}{l}\text { Wrong driving path, normal } \\
\text { conditions (21) }\end{array}$ & $\begin{array}{l}\text { Loss of control }(\mathrm{A}) \text { on curve } \\
\text { without braking }\end{array}$ & $60 / 60$ & (2) & No \\
\hline Wrong driving path, dark (21) & $\begin{array}{l}\text { Car was under control (B) until } \\
\text { the crash on curve }\end{array}$ & $80 / 80$ & (2) & No \\
\hline $\begin{array}{l}\text { Wrong driving path, wet road } \\
\text { surface and dark (20) }\end{array}$ & $\begin{array}{l}\text { Car was under control (B) until } \\
\text { the crash on straight section }\end{array}$ & $75 / 80$ & $(2),(8)$ & No \\
\hline $\begin{array}{l}\text { Wrong driving path, snowy } \\
\text { road surface, sleet }(21)\end{array}$ & $\begin{array}{c}\text { Control was unknown on } \\
\text { curve }\end{array}$ & $60 / 60$ & (3), (8) & No \\
\hline $\begin{array}{l}\text { Wrong judgment on own } \\
\text { possibilities to proceed, snowy } \\
\text { road surface }(21)\end{array}$ & $\begin{array}{l}\text { Loss of control (A) on curve, } \\
\text { braking status unknown }\end{array}$ & $45 / 50$ & (3), (8) & No \\
\hline $\begin{array}{l}\text { Wrong judgment on own } \\
\text { possibilities to proceed, icy } \\
\text { road surface, sleet }(21)\end{array}$ & $\begin{array}{l}\text { Loss of control (A) on curve } \\
\text { after overtaking, braking } \\
\text { status unknown }\end{array}$ & $110 / 100$ & $(3),(4),(8)$ & No \\
\hline $\begin{array}{l}\text { Steering error, normal } \\
\text { conditions }(20)\end{array}$ & $\begin{array}{c}\text { Loss of control (A) on straight } \\
\text { section, braking status } \\
\text { unknown }\end{array}$ & $100 / 100$ & (1) & No \\
\hline $\begin{array}{l}\text { Steering error, wet road } \\
\text { surface, dark (20) }\end{array}$ & $\begin{array}{c}\text { Loss of control }(\mathrm{A}) \text { on straight } \\
\text { section, braking status } \\
\text { unknown }\end{array}$ & $80 / 80$ & (3) & No \\
\hline $\begin{array}{l}\text { Steering error, icy road surface, } \\
\text { tarmac }(20)\end{array}$ & $\begin{array}{c}\text { Loss of control (A) on straight } \\
\text { section, braking status } \\
\text { unknown }\end{array}$ & $70 / 100$ & (3), (8) & No \\
\hline $\begin{array}{l}\text { Steering error, icy road surface, } \\
\text { dark (20) }\end{array}$ & $\begin{array}{c}\text { Loss of control }(\mathrm{A}) \text { on straight } \\
\text { section, braking status } \\
\text { unknown }\end{array}$ & $80 / 80$ & (3), (8) & No \\
\hline $\begin{array}{l}\text { Steering error, snowy road } \\
\text { surface, sleet }(21)\end{array}$ & $\begin{array}{l}\text { Loss of control (A) on curve, } \\
\text { braking status unknown }\end{array}$ & $75 / 100$ & (3), (8) & No \\
\hline $\begin{array}{l}\text { Steering error, snowy road } \\
\text { surface, snowfall (20) }\end{array}$ & $\begin{array}{c}\text { Loss of control }(\mathrm{A}) \text { on straight } \\
\text { section, braking status } \\
\text { unknown }\end{array}$ & $80 / 80$ & (3), (8) & No \\
\hline $\begin{array}{l}\text { Steering error, snowy road } \\
\text { surface }(21)\end{array}$ & $\begin{array}{l}\text { Loss of control (A) on curve, } \\
\text { braking status unknown }\end{array}$ & $90 / 100$ & (3) & No \\
\hline $\begin{array}{l}\text { Steering error, snowy and } \\
\text { locally icy road surface ( } 24)\end{array}$ & $\begin{array}{l}\text { Loss of control (A) on curve } \\
\text { after overtaking, braking } \\
\text { status unknown }\end{array}$ & $80 / 80$ & $(3),(4),(8)$ & $\begin{array}{l}\text { On locally icy } \\
\text { conditions }\end{array}$ \\
\hline $\begin{array}{c}\text { Steering error, locally icy road } \\
\text { surface }(20)\end{array}$ & $\begin{array}{l}\text { Loss of control (A) on straight } \\
\text { section without braking }\end{array}$ & $80 / 80$ & (3), (8) & $\begin{array}{l}\text { On locally icy } \\
\text { conditions }\end{array}$ \\
\hline $\begin{array}{l}\text { Steering error, locally icy road } \\
\text { surface, fog, dark (20) }\end{array}$ & $\begin{array}{c}\text { Loss of control (A) on straight } \\
\text { section, braking status } \\
\text { unknown }\end{array}$ & $90 / 100$ & (3) & $\begin{array}{l}\text { On locally icy } \\
\text { conditions }\end{array}$ \\
\hline $\begin{array}{l}\text { Steering error, snowy road } \\
\text { surface (20) }\end{array}$ & $\begin{array}{c}\text { Car was not steered }(\mathrm{C}) \text { on } \\
\text { straight section }\end{array}$ & $87 / 80$ & (5), (8) & No \\
\hline $\begin{array}{l}\text { Other driving-related act, } \\
\text { snowy road surface, rainfall, } \\
\text { dark (20) }\end{array}$ & $\begin{array}{c}\text { Loss of control (A) on straight } \\
\text { section, braking status } \\
\text { unknown }\end{array}$ & $50 / 50$ & (3) & No \\
\hline $\begin{array}{l}\text { Overtaking or approaching an } \\
\text { intersection without proper } \\
\text { anticipation, dark (23) }\end{array}$ & $\begin{array}{l}\text { Overtaking and crash with a } \\
\text { car on lane of opposite } \\
\text { direction, car was under } \\
\text { control (B) }\end{array}$ & $85 / 80$ & (4) & $\begin{array}{c}\text { On the } \\
\text { whereabouts of } \\
\text { other cars }\end{array}$ \\
\hline
\end{tabular}

To avoid the studied crashes, several requirements for the operation of a CAV were recognized. In 13 crashes, the CAV should have taken the weather conditions into account 
and potentially adjusted the speed according to the conditions to avoid the collision (action 3 ). In these cases, the driver lost control of the car, and weather conditions were adverse. In two cases, the driver lost control after overtaking, and in one case, the driver hit the car in the oncoming lane while overtaking. To prevent crashes in overtaking cases, the CAV should ensure that the overtaking is safe. For instance, overtaking should be able to be done at a safe speed, while obeying the speed limit and taking prevailing weather and road conditions into account. In addition, real-time information on all oncoming vehicles via communication systems would be needed to assist the CAV to recognize safe overtaking situations. V2V or V2I communication would likely have helped to avoid four crashes, because the CAV could have received information on locally icy conditions or oncoming vehicles before beginning to overtake on two-lane roads. The information would help to make the decision on whether it was possible to overtake safely or not. In 11 cases, the location of the lane would have needed to be digitally determined (action 8), because the painted lane markings were invisible or only partially visible.

\subsection{Single-Car Crashes}

Single-car crashes (Table 2) were typically caused by steering errors $(n=9)$ or incorrect observations of the car's location or wrong judgement on the movement $(n=6)$. Loss of control of the car $(\mathrm{A}, \mathrm{n}=17)$ was identified as the pre-crash event in almost all crashes.

Table 2. Characteristics of the 18 studied single-car crashes.

\begin{tabular}{|c|c|c|c|c|}
\hline $\begin{array}{c}\text { Immediate Risk Factor (Code } \\
\text { of the Crash Type in } \\
\text { Parentheses) }\end{array}$ & $\begin{array}{l}\text { Control of the Car in the } \\
\text { Pre-Crash Event }\end{array}$ & $\begin{array}{c}\text { Estimated } \\
\text { Speed/Speed Limit } \\
(\mathrm{km} / \mathrm{h})\end{array}$ & $\begin{array}{l}\text { Requirements } \\
\text { for CAV }\end{array}$ & $\begin{array}{c}\text { V2V or V2I } \\
\text { Communication } \\
\text { Need }\end{array}$ \\
\hline $\begin{array}{l}\text { Incorrect observation of car's } \\
\text { location on roadway, } \\
\text { gravel-paved road (80) }\end{array}$ & $\begin{array}{l}\text { Loss of control (A) on straight } \\
\text { section, braking status unknown }\end{array}$ & $70 / 80$ & $(2),(8)$ & No \\
\hline $\begin{array}{l}\text { Wrong judgment on own } \\
\text { possibilities to proceed, snowy } \\
\text { road surface (84) }\end{array}$ & $\begin{array}{l}\text { Loss of control (A) on curve } \\
\text { without braking }\end{array}$ & $60 / 80$ & (3), (8) & No \\
\hline $\begin{array}{l}\text { Wrong judgment on own } \\
\text { possibilities to proceed, } \\
\text { gravel-paved road, dark (81) }\end{array}$ & $\begin{array}{l}\text { Loss of control (A) on straight } \\
\text { section, braking status unknown }\end{array}$ & $90 / 80$ & $(1),(8)$ & No \\
\hline $\begin{array}{l}\text { Wrong judgment on own } \\
\text { possibilities to proceed, } \\
\text { gravel-paved road, dark (83) }\end{array}$ & $\begin{array}{l}\text { Loss of control (A) on curve with } \\
\text { braking }\end{array}$ & $80 / 80$ & $(1),(8)$ & No \\
\hline $\begin{array}{l}\text { Wrong judgment on own } \\
\text { possibilities to proceed, } \\
\text { gravel-paved road, icy road } \\
\text { surface, snowfall (83) }\end{array}$ & $\begin{array}{l}\text { Loss of control (A) on curve, } \\
\text { braking status unknown }\end{array}$ & $\mathrm{NA} / 80$ & $(3),(8)$ & No \\
\hline $\begin{array}{l}\text { Wrong judgment on own } \\
\text { possibilities to proceed, normal } \\
\text { conditions (81) }\end{array}$ & $\begin{array}{l}\text { Loss of control (A) on straight } \\
\text { section after overtaking, braking } \\
\text { status unknown }\end{array}$ & $\mathrm{NA} / 80$ & $(1),(4),(8)$ & No \\
\hline $\begin{array}{l}\text { Steering error, snowy road } \\
\text { surface, snowfall, dark (84) }\end{array}$ & $\begin{array}{l}\text { Loss of control (A) on curve } \\
\text { without braking }\end{array}$ & NA/100 & (3), (8) & No \\
\hline $\begin{array}{c}\text { Steering error, wet road surface, } \\
\text { rainfall (81) }\end{array}$ & $\begin{array}{l}\text { Loss of control (A) on straight } \\
\text { section, braking status unknown }\end{array}$ & NA/100 & (3) & No \\
\hline $\begin{array}{l}\text { Steering error, icy road surface } \\
(80)\end{array}$ & $\begin{array}{l}\text { Loss of control (A) on straight } \\
\text { section, braking status unknown }\end{array}$ & $80 / 80$ & (3), (8) & No \\
\hline $\begin{array}{l}\text { Steering error, icy road surface } \\
(80)\end{array}$ & $\begin{array}{l}\text { Loss of control (A) on curve, } \\
\text { braking status unknown }\end{array}$ & $75 / 80$ & (3), (8) & No \\
\hline
\end{tabular}


Table 2. Cont.

\begin{tabular}{|c|c|c|c|c|}
\hline $\begin{array}{c}\text { Immediate Risk Factor (Code } \\
\text { of the Crash Type in } \\
\text { Parentheses) }\end{array}$ & $\begin{array}{c}\text { Control of the Car in the } \\
\text { Pre-Crash Event }\end{array}$ & $\begin{array}{c}\text { Estimated } \\
\text { Speed/Speed Limit } \\
(\mathrm{km} / \mathrm{h})\end{array}$ & $\begin{array}{l}\text { Requirements } \\
\text { for CAV }\end{array}$ & $\begin{array}{c}\text { V2V or V2I } \\
\text { Communication } \\
\text { Need }\end{array}$ \\
\hline $\begin{array}{l}\text { Steering error, wet road surface, } \\
\text { rainfall (84) }\end{array}$ & $\begin{array}{l}\text { Loss of control (A) on straight } \\
\text { section, braking status unknown }\end{array}$ & $120 / 120$ & (3) & No \\
\hline $\begin{array}{l}\text { Steering error, icy road surface } \\
\qquad(81)\end{array}$ & $\begin{array}{l}\text { Loss of control (A) on straight } \\
\text { section after overtaking, braking } \\
\text { status unknown }\end{array}$ & $80 / 80$ & $(3),(4),(8)$ & No \\
\hline $\begin{array}{l}\text { Steering error, wet road surface } \\
\qquad(80)\end{array}$ & $\begin{array}{l}\text { Loss of control (A) on straight } \\
\text { section, braking status unknown }\end{array}$ & $\mathrm{NA} / 60$ & (3) & No \\
\hline $\begin{array}{c}\text { Steering error, icy road surface, } \\
\text { dark (84) }\end{array}$ & $\begin{array}{l}\text { Loss of control (A) on curve, } \\
\text { braking status unknown }\end{array}$ & $70 / 80$ & (3), (8) & No \\
\hline $\begin{array}{l}\text { Steering error, normal conditions } \\
(80)\end{array}$ & $\begin{array}{l}\text { Loss of control (A) on straight } \\
\text { section without braking }\end{array}$ & $95 / 80$ & (1) & No \\
\hline $\begin{array}{l}\text { Other anticipation-related act, } \\
\text { normal conditions }(84)\end{array}$ & $\begin{array}{l}\text { Loss of control (A) on curve, } \\
\text { without braking }\end{array}$ & $110 / 100$ & (1) & No \\
\hline $\begin{array}{l}\text { Immediate error unclear, normal } \\
\text { conditions (84) }\end{array}$ & $\begin{array}{c}\text { Loss of control (A) on curve, } \\
\text { without braking }\end{array}$ & $90 / 100$ & (1) & No \\
\hline $\begin{array}{l}\text { Other driver-related act, } \\
\text { snowfall (99) }\end{array}$ & $\begin{array}{l}\text { Car was under control (B) until } \\
\text { the crash in parking area }\end{array}$ & $20 / 30$ & $(2),(8)$ & No \\
\hline
\end{tabular}

To avoid the studied crashes, several requirements for the operation of a CAV were recognized. In 10 crashes, the CAV should have taken the weather conditions into account and potentially decelerated to avoid the collision (action 3). In these cases, the driver lost control of the car, and weather conditions were adverse. In 12 crashes, lane markings were invisible or only partially visible. The CAVs' V2V or V2I communications were not recognised to enhance the possibility of preventing the studied single-car crashes.

\subsection{Intersection and Rear-End Crashes}

In intersection crashes (Table 3), the driver with the obligation to yield did not recognize the other involved car $(n=4)$ or made an incorrect observation of the other involved car or traffic environment $(n=3)$. In all the intersection crashes studied, the car was under the driver's control (B), which reflected that the driver was not able to recognize the danger at the intersection. According to the TTC analysis, the CAV would have recognized the other involved car in a collision course at least 1.0 or $1.5 \mathrm{~s}$ before the crash in three cases, and $0.5 \mathrm{~s}$ before the crash in another three cases, assuming that the other involved car would not be recognised until it reached the intersection area. To avoid intersection crashes, CAVs should be able to recognize approaching vehicles at intersections and assess the right moment to proceed. V2V or V2I communication of the location of other cars would help to recognise the danger.

Table 3 shows that to avoid a single rear-end crash due to an incorrect observation, the CAV should be able to operate in adverse weather conditions and make adequate and right observations on another car's movement. In adverse conditions, vehicle speed should likely be decreased. In this case, the TTC value was $2 \mathrm{~s}$, but the driver was unable to prevent the crash due to incorrect observation. In the rear-end crash due to loss of control after overtaking, the driver was not able to prevent the crash due to loss of control, and hence, it would be important to ensure that overtaking is safe following the speed limit. V2V or V2I communication of the other car's location would assist CAVs in preventing these crashes. 
Table 3. Characteristics of the eight studied intersection crashes and the two rear-end crashes from the at-fault driver's point of view.

\begin{tabular}{|c|c|c|c|c|}
\hline $\begin{array}{l}\text { Immediate Risk Factor (Code of the } \\
\text { Crash Type in Parentheses) }\end{array}$ & $\begin{array}{l}\text { Control of the Car in the } \\
\text { Pre-Crash Event }\end{array}$ & $\begin{array}{c}\text { Estimated } \\
\text { Speed/Speed Limit } \\
(\mathrm{km} / \mathrm{h}), \text { TTC }\end{array}$ & $\begin{array}{l}\text { Requirements } \\
\text { for CAV }\end{array}$ & $\begin{array}{c}\text { V2V or V2I } \\
\text { Communication Need }\end{array}$ \\
\hline \multicolumn{5}{|l|}{ Intersection crashes: } \\
\hline $\begin{array}{c}\text { Driver did not recognize other } \\
\text { involved car, icy road surface }(53)\end{array}$ & $\begin{array}{l}\text { Car was under control (B), } \\
\text { turning at intersection }\end{array}$ & $\begin{array}{c}10 / 80 \\
\text { TTC: } 0.5 \mathrm{~s}\end{array}$ & $(6),(8)$ & $\begin{array}{c}\text { On the whereabouts of } \\
\text { other cars }\end{array}$ \\
\hline $\begin{array}{l}\text { Driver did not recognize other } \\
\text { involved car, normal conditions }(30)\end{array}$ & $\begin{array}{l}\text { Car was under control (B), } \\
\text { turning at intersection }\end{array}$ & & (6) & $\begin{array}{c}\text { On the whereabouts of } \\
\text { other cars }\end{array}$ \\
\hline $\begin{array}{l}\text { Driver did not recognize other } \\
\text { involved car, gravel-paved road (40) }\end{array}$ & $\begin{array}{l}\text { Car was under control (B), going } \\
\text { straight ahead at intersection }\end{array}$ & $\begin{array}{l}30 / 80 \\
\text { TTC: } 1.0 \mathrm{~s}\end{array}$ & $(6),(8)$ & $\begin{array}{c}\text { On the whereabouts of } \\
\text { other cars }\end{array}$ \\
\hline $\begin{array}{l}\text { Driver did not recognize other } \\
\text { involved car, wet road surface, } \\
\text { rainfall (40) }\end{array}$ & $\begin{array}{l}\text { Car was under control (B), going } \\
\text { straight ahead at intersection }\end{array}$ & $\begin{array}{l}\text { 40/50 } \\
\text { TTC: } 0 \mathrm{~s}\end{array}$ & (6) & $\begin{array}{c}\text { On the whereabouts of } \\
\text { other cars }\end{array}$ \\
\hline $\begin{array}{l}\text { Overtaking or approaching an } \\
\text { intersection without proper } \\
\text { anticipation, wet road surface, } \\
\text { rainfall, dark }(40)\end{array}$ & $\begin{array}{l}\text { Car was under control (B), going } \\
\text { straight ahead at intersection }\end{array}$ & $\begin{array}{l}30 / 50 \\
\text { TTC: } 0 \mathrm{~s}\end{array}$ & (6) & $\begin{array}{c}\text { On the whereabouts of } \\
\text { other cars }\end{array}$ \\
\hline $\begin{array}{l}\text { Incorrect observation of traffic } \\
\text { environment, normal conditions (53) }\end{array}$ & $\begin{array}{l}\text { Car was under control (B), } \\
\text { turning at intersection }\end{array}$ & $\begin{array}{l}20 / 50 \\
\text { TTC: } 1.0 \mathrm{~s}\end{array}$ & (6) & $\begin{array}{c}\text { On the whereabouts of } \\
\text { other cars }\end{array}$ \\
\hline $\begin{array}{l}\text { Incorrect observation of traffic } \\
\text { environment, normal conditions (53) }\end{array}$ & $\begin{array}{l}\text { Car was under control (B), } \\
\text { turning at intersection }\end{array}$ & $\begin{array}{l}\text { 10/100 } \\
\text { TTC: } 0.5 \mathrm{~s}\end{array}$ & $(6),(8)$ & $\begin{array}{c}\text { On the whereabouts of } \\
\text { other cars }\end{array}$ \\
\hline $\begin{array}{c}\text { Incorrect observation of other } \\
\text { involved car, wet road surface, } \\
\text { rainfall (30) }\end{array}$ & $\begin{array}{l}\text { Car was under control (B), } \\
\text { turning at intersection }\end{array}$ & $\begin{array}{l}\text { 10/100 } \\
\text { TTC: } 0.5 \mathrm{~s}\end{array}$ & (6) & $\begin{array}{c}\text { On the whereabouts of } \\
\text { other cars }\end{array}$ \\
\hline $\begin{array}{c}\text { Rear-end crashes: } \\
\text { Incorrect observation of other } \\
\text { involved car, snowy road surface, } \\
\text { sleet, dark (9) }\end{array}$ & $\begin{array}{l}\text { Car was under control (B) until } \\
\text { the crash on a curve }\end{array}$ & $\begin{array}{l}80 / 80 \\
\text { TTC: } 2 \mathrm{~s}\end{array}$ & (3), (7), (8) & $\begin{array}{c}\text { On the whereabouts of } \\
\text { other cars }\end{array}$ \\
\hline $\begin{array}{l}\text { Wrong driving path, normal } \\
\text { conditions (1) }\end{array}$ & $\begin{array}{l}\text { Loss of control (A) on straight } \\
\text { section after overtaking, braking } \\
\text { status unknown }\end{array}$ & $\begin{array}{l}\text { 85/80 } \\
\text { TTC: } 0 \mathrm{~s}\end{array}$ & (4) & $\begin{array}{c}\text { On the whereabouts of } \\
\text { other cars }\end{array}$ \\
\hline
\end{tabular}

\section{Discussion}

One of the benefits of automated driving systems is that they can likely operate safer in normal traffic conditions than humans, but if something extraordinary occurs that is not programmed in the system, the system may not be able to handle the situation [38]. Therefore, it is important to learn about crash-related factors and needed features from the investigations of the current crashes of driver-managed cars. In this study, we investigated the immediate risk factors and state of car control in Finnish fatal passenger car crashes, and evaluated what actions a CAV should take to avoid these crashes. We focused solely on crashes in which a driving error was evaluated to be the immediate risk factor, and other driver-related factors (e.g., a driver's physical condition or an excessive speed) were not identified to have an impact on the crash outcome. These other driver-related factors can assumedly be removed by CAVs, and the CAVs would likely operate differently in these cases than human drivers. Consequently, it was not necessary to analyse those cases.

Of the 48 analysed crashes, 33 (69\%) were loss-of-control cases. In most of the loss-ofcontrol cases $(n=22)$, weather (e.g., snowfall) or road conditions (e.g., icy road surface) caused challenging conditions to operate, and hence, the CAV should have been able to adjust the speed according to the conditions of each road section (action 3 ) to operate safely in these circumstances. In the analysed crashes, speeds were within the speed limit or exceeded the limit by less than $20 \mathrm{~km} / \mathrm{h}$. This meant that in many cases with adverse weather conditions, the safe speed was less than the speed limit. Crashes due to loss of control were also identified in normal weather and road conditions, when other factors along with a driving error were not typically identified. In normal weather conditions and in loss-of-control cases, the avoidance of steering errors (action 1) and an ability to keep the car inside the lane (action 2) would theoretically be simple to implement. However, the road network is wide and versatile in Finland; e.g., it includes gravel-paved roads and 
multiple types of road infrastructure. It would probably take a significant amount of time to develop driving automation that was able to operate in various conditions and versatile road environments, which makes the solution much more complex. If a CAV is not able to operate in all situations, the potential safety effects are not fully realized, which is also the case when CAV market penetration rate remains low. Consequently, it is necessary to develop CAVs' abilities to operate in all conditions, or at least in as many as possible.

In $13(27 \%)$ of the studied crashes, the car was under control during the occurrence of the crash. In some of these cases, the immediate risk factor was a wrong driving path or overtaking, but most of these cases were intersection crashes $(n=8)$, in which the driver did not typically recognize the other involved car. We investigated the possibility of the CAV to avoid intersection crashes with TTC analysis. In other studies [27,39], the threshold TTC value was typically about $1.5 \mathrm{~s}$, which reflected a high collision risk and when an automatic emergency braking system should activate at the latest. According to the calculations and assumed threshold value of $1.5 \mathrm{~s}$, only one of eight intersection crashes could hypothetically be avoided by a CAV. In a single rear-end crash due to an incorrect observation, the TTC value was $2 \mathrm{~s}$, and hence, the collision could potentially have been avoided by the CAV if the CAV had been able to make correct observations. In the other rear-end crash, the TTC value was $0 \mathrm{~s}$, but the crash was due to loss of control after overtaking, which was the primary factor to focus on instead of the TTC value.

Communication between the vehicles or the vehicle and the infrastructure is likely an essential part of the successful implementation of CAVs [40]. In this study, it was found that communication would help to avoid crashes when the weather conditions surprisingly changed or when the other involved vehicle was not recognised in intersection crashes. In total, it was found that in 14 (29\%) of the 48 crashes, V2V or V2I communication would have been a crucial factor for crash avoidance. Most of these cases $(n=11)$ related to recognising the approaching car, or the danger at an intersection or in a rear-end accident. Three cases related to site-specific icy conditions, in which information on the slippery road surface would help to set a safe speed.

Current lane-keeping assistance systems in SAE level 2 are based on the recognition of lane markings [41], but this seems not to be a safe solution to determine a CAV's location in the roadway, because the lane markings were not clearly visible or the markings did not exist in 27 (56\%) cases. Digital lane markings and high-definition maps (see, e.g., [42]) are recommended as a solution to determine the location of a vehicle in order to extend the operational capability of CAVs. However, the development of digital lane markings in the wide road network may be a long process, and hence, this should be a supplementary way to determine the lane position in addition to lane markings.

The exact parameters of advanced CAVs are not currently known, because connected and automated driving systems are still under development. Consequently, previous studies have made potentially varying assumptions on the operational capability of the systems, which have probably led to wide-ranging results on the potential safety effects of the CAVs. In this study, we aimed to disclose and discuss the factors that are critical in order to avoid crashes of current driver-managed cars if the cars involved in the crashes were replaced by CAVs. While the analysed crash data were based on in-depth investigations, the provided results are not immediately applicable to the design and programming of CAVs, because the results are not detailed enough. We identified four factors that are especially important in the development of CAVs according to the analysed crashes:

- Loss of control of the car in an adverse weather condition is a typical pre-crash event, and hence, speed should be adjusted according to the road and weather conditions. In adverse conditions, the safe speed is likely lower than the speed limit.

- Crashes in which the car was under control or the car was not steered were typically due to a driver's incorrect observation or wrong driving path. In order to prevent these types of crashes, errors related to observations of other road users and traffic environments should be avoided. This is a challenging requirement, because fatal 
crashes occur in diverse traffic environments, including, for example, the lower road network, in which some roads are gravel-paved.

- Communication technologies (e.g., V2V and V2I) are necessary in recognising possible conflicts and hazardous situations; e.g., at intersections and sudden changes in road conditions.

- CAVs should be developed to follow digital lane markings or other digital data on the location of the roadway, because the painted lane markings are an uncertain way to assist the vehicle in keeping its supposed lane position.

Although we focused on the elimination of driving errors in this study from the perspective of CAVs' safety potential, it should be noted that some other risk factors associated with crashes were not automatically eliminated. For instance, factors related to the vehicle or the road environment could still enable the occurrence of crashes when CAVs become more prevalent [43]. It should also be noted as a limitation of this study that although the immediate risk factors and other variables were based on in-depth investigations, some factors may have been difficult to determine and investigate. Therefore, each variable could not be considered as completely certain. In addition, although the number of analysed cases was rather small, the data set enabled a qualitative analysis of each case and CAVs ${ }^{\prime}$ needed features, which is typically not possible in a quantitative research with a larger data set.

\section{Conclusions}

We analysed needed features of CAVs to prevent actual passenger car crashes in which the immediate risk factor was a driving error. We found that most of the analysed crashes were due to loss of control. To prevent these crashes, CAVs should, for instance, adjust their speed according to the road and weather conditions. Observational errors were typical causative factors of the crashes in which the car was under control or the car was not steered. A reliable capability to recognize other road users and risks in the traffic environments is also an important CAV feature according to the analysis.

There is only limited knowledge on the needed features of CAVs to avoid actual crashes in which a driving error was the immediate risk factor. This study increases knowledge of the needed safety features of CAVs by learning from the previous crashes of driver-managed cars. While CAV operation differs from human driver operation, the analysis indicated potential key areas on which to focus in the development of CAVs in terms of crash avoidance and safe operation. Hence, the results can assist car manufacturers, technology developers, and companies, as well as public authorities, in pursuing safer driving automation.

Future research should deepen the analysis of the needed features of CAVs, such as the investigation of safe speed in cases due to a loss of control. Utilising a larger data set, if and how a CAV could possibly avoid being in this kind of crash through safe actions throughout its operations should also be studied. CAVs should also be tested in more diverse traffic and road environments to learn more about the possibilities of operating safely in those environments.

Author Contributions: Conceptualization, R.U.; methodology, R.U.; investigation, R.U.; writingoriginal draft preparation, R.U. and M.P.; writing-review and editing, R.U. and M.P.; funding acquisition, R.U. Both authors have read and agreed to the published version of the manuscript.

Funding: This research was funded by the Finnish Crash Data Institute.

Institutional Review Board Statement: Not applicable.

Informed Consent Statement: Not applicable.

Conflicts of Interest: The authors declare no conflict of interest. 


\section{Appendix A}

Table A1. Circumstances and other crash-related factors of the 48 studied crashes.

\begin{tabular}{|c|c|c|}
\hline Characteristics and Variables & $\mathrm{n}=48$ & $\%=100 \%$ \\
\hline \multicolumn{3}{|l|}{ Crash types } \\
\hline -Opposite directions (no turning) & 20 & $42 \%$ \\
\hline -Opposite directions (turning) & 2 & $5 \%$ \\
\hline -Single-car crashes: & 17 & $35 \%$ \\
\hline -Intersecting directions (no turning) & 3 & $6 \%$ \\
\hline -Intersecting directions (turning) & 3 & $6 \%$ \\
\hline -Same directions (no turning) & 2 & $4 \%$ \\
\hline -Other & 1 & $2 \%$ \\
\hline \multicolumn{3}{|l|}{ Action of the driver to prevent the crash } \\
\hline No action & 18 & $38 \%$ \\
\hline The driver tried to control the vehicle & 12 & $25 \%$ \\
\hline The driver decelerated & 2 & $4 \%$ \\
\hline Action was not possible to identify & 16 & $33 \%$ \\
\hline \multicolumn{3}{|l|}{ Road conditions } \\
\hline -Dry weather & 18 & $38 \%$ \\
\hline -Icy road surface & 12 & $25 \%$ \\
\hline -Snowy road surface & 10 & $21 \%$ \\
\hline -Wet road surface & 8 & $17 \%$ \\
\hline \multicolumn{3}{|l|}{ Weather } \\
\hline -Cloudy & 19 & $40 \%$ \\
\hline -Sunny & 12 & $25 \%$ \\
\hline -Rain & 6 & $13 \%$ \\
\hline -Snowfall & 4 & $8 \%$ \\
\hline -Sleet & 4 & $8 \%$ \\
\hline -Fog & 1 & $2 \%$ \\
\hline -Other/not available & 2 & $4 \%$ \\
\hline \multicolumn{3}{|l|}{ Lightness } \\
\hline -Daylight & 27 & $56 \%$ \\
\hline -Dim & 8 & $17 \%$ \\
\hline -Dark & 13 & $27 \%$ \\
\hline \multicolumn{3}{|l|}{ Time of day } \\
\hline$-0: 00-5: 59$ & 2 & $4 \%$ \\
\hline$-6: 00-11: 59$ & 14 & $29 \%$ \\
\hline$-12: 00-17: 59$ & 24 & $50 \%$ \\
\hline$-18: 00-23: 59$ & 8 & $17 \%$ \\
\hline \multicolumn{3}{|l|}{ At-fault car's speed } \\
\hline$-30 \mathrm{~km} / \mathrm{h}$ or less & 8 & $17 \%$ \\
\hline$-31-50 \mathrm{~km} / \mathrm{h}$ & 3 & $6 \%$ \\
\hline$-51-70 \mathrm{~km} / \mathrm{h}$ & 6 & $13 \%$ \\
\hline$-71-90 \mathrm{~km} / \mathrm{h}$ & 20 & $42 \%$ \\
\hline$-91-110 \mathrm{~km} / \mathrm{h}$ & 5 & $10 \%$ \\
\hline -Not available & 6 & $13 \%$ \\
\hline \multicolumn{3}{|l|}{ Road surface } \\
\hline -Hard road surface & 42 & $88 \%$ \\
\hline -Tarmac & 1 & $2 \%$ \\
\hline -Gravel paved road & 5 & $10 \%$ \\
\hline
\end{tabular}




\section{Appendix B}

Visualisation of the different crash types among the analysed crashes.

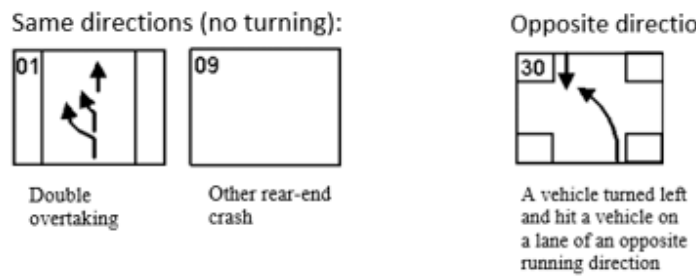

Opposite directions (no turning):

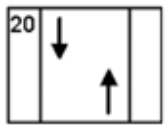

Head-on crash on a straight section

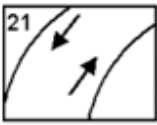

Head-on crash

on a curve

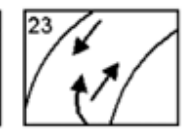

Head-on crash overtaking on a road due to an curve vehicle

Intersecting directions (no turning):

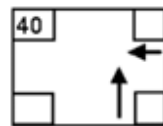

Driving straight through, intersecting direction

Single-car crashes:

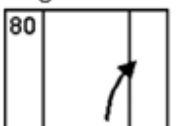

Drifted out of the right side of the road on a straight section

Other crash:

99

Other crash tersecting directions (turning):

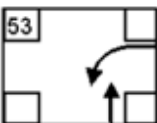

A vehicle turned lef and hit a straigh going vehicle

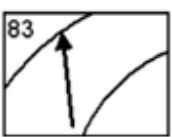

Drifted out of the left side of the road on a right curve

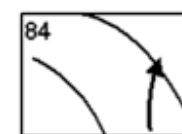

Drifted out of the right side of the road on a left curve

\section{References}

1. Belokurov, V.; Spodarev, R.; Belokurov, S. Determining passenger traffic as important factor in urban public transport system. Transp. Res. Procedia 2020, 50, 52-58. [CrossRef]

2. Pöllänen, M.; Liljamo, T.; Kallionpää, E.; Liimatainen, H. Is There Progress towards Environmental Sustainability among Road Haulage Companies. Sustainability 2021, 13, 5845. [CrossRef]

3. Enoch, M.P.; Cross, R.; Potter, N.; Davidson, C.; Taylor, S.; Brown, R.; Huang, H.; Parsons, J.; Tucker, S.; Wynne, E.; et al. Future local passenger transport system scenarios and implications for policy and practice. Transp. Policy 2020, 90, 52-67. [CrossRef]

4. Utriainen, R.; Pöllänen, M. Review on mobility as a service in scientific publications. Res. Transp. Bus. Manag. 2018, 27, 15-23. [CrossRef]

5. Wang, L.; Zhong, H.; Ma, W.; Abdel-Aty, M.; Park, J. How many crashes can connected vehicle and automated vehicle technologies prevent: A meta-analysis. Accid. Anal. Prev. 2020, 136, 105299. [CrossRef] [PubMed]

6. Waymo. On the road to fully self-driving. In Waymo Safety Report; Waymo: Mountain View, CA, USA, 2018.

7. Fagnant, D.J.; Kockelman, K. Preparing a nation for autonomous vehicles: Opportunities, barriers and policy recommendations. Transp. Res. Part A 2015, 77, 167-181. [CrossRef]

8. U.S. Department of Transportation. Preparing for the Future of Transportation: Automated Vehicles 3.0; U.S. Department of Transportation: Washington, DC, USA, 2018.

9. SAE. Taxonomy and Definitions for Terms Related to Driving Automation Systems for On-Road Motor Vehicles; SAE: Warrendale, PA, USA, 2018.

10. Bagloee, S.A.; Tavana, M.; Asadi, M.; Oliver, T. Autonomous vehicles: Challenges, opportunities, and future implications for transportation policies. J. Mod. Transp. 2016, 24, 284-303. [CrossRef]

11. Elliott, D.; Keen, W.; Miao, L. Recent advances in connected and automated vehicles. J. Traffic Transp. Eng. 2019, 6, 109-131. [CrossRef] 
12. European Commission. Digital Technologies Make Transport and Mobility Smarter, Safer and Greener. Available online: https:/ / ec.europa.eu/digital-single-market/en/mobility (accessed on 30 April 2020).

13. Singh, S. Critical reasons for crashes investigated in the National Motor Vehicle Crash Causation Survey. In Traffic Safety Facts Report No. DOT HS 812 115; National Highway Traffic Safety Administration: Washington, DC, USA, 2015.

14. Morando, M.M.; Tian, Q.; Truong, L.T.; Vu, H.L. Studying the Safety Impact of Autonomous Vehicles Using Simulation-Based Surrogate Safety Measures. J. Adv. Transp. 2018, 2018, 6135183. [CrossRef]

15. Combs, T.S.; Sandt, L.S.; Clamann, M.P.; McDonald, N.C. Automated Vehicles and Pedestrian Safety: Exploring the Promise and Limits of Pedestrian Detection. Am. J. Prev. Med. 2019, 56, 1-7. [CrossRef]

16. OECD. Safer Roads with Automated Vehicles? International Transport Forum; OECD: Paris, France, 2018.

17. World Health Organization. Global Status Report on Road Safety 2018; World Health Organization: Geneva, Switzerland, 2018.

18. Litman, T. Autonomous Vehicle Implementation Predictions: Implications for Transport Planning; Victoria Transport Policy Institute: Victoria, BC, Canada, 2020.

19. NTSB. Collision Between Vehicle Controlled by Developmental Automated Driving System and Pedestrian. In Proceedings of the Board Meeting, Washington, DC, USA, 19 November 2019; Available online: https:/ / www.ntsb.gov/news/events/Documents / 2019-HWY18MH010-BMG-abstract.pdf (accessed on 26 March 2020).

20. NTSB. Preliminary Report. Highway HWY18FH011. Available online: https://www.ntsb.gov/investigations/AccidentReports / Reports/HWY18FH011-preliminary.pdf (accessed on 26 March 2020).

21. European Commission. Annual Accident Report; European Commission, Directorate General for Transport: Brussels, Belgium, 2018.

22. Georgis, N.; Carpio, F.; Hwang, P.J. Automatic Speed Limit Adjust for Road Conditions. U.S. Patent US8311734B2, 13 November 2012.

23. Shetty, A.; Yu, M.; Kurzhanskiy, A.; Grembek, O.; Tavafoghi, H.; Varaiya, P. Safety challenges for autonomous vehicles in the absence of connectivity. Transp. Res. Part C Emerg. Technol. 2021, 128, 103133. [CrossRef]

24. Tibljaš, A.D.; Giuffrè, T.; Surdonja, S.; Trubia, S. Introduction of autonomous vehicles: Roundabouts design and safety performance. Sustainability 2018, 10, 1060. [CrossRef]

25. Virdi, N.; Grzybowska, H.; Waller, S.T.; Dixit, V. A safety assessment of mixed fleets with connected and autonomous vehicles using the surrogate safety assessment module. Accid. Anal. Prev. 2019, 131, 95-111. [CrossRef]

26. Jeong, E.; Oh, C.; Lee, S. Is vehicle automation enough to prevent crashes? Role of traffic operations in automated driving environments for traffic safety. Accid. Anal. Prev. 2017, 104, 115-124. [CrossRef]

27. Papadoulis, A.; Quddus, M.; Imprialou, M. Evaluating the safety impact of connected and autonomous vehicles on motorways. Accid. Anal. Prev. 2019, 124, 12-22. [CrossRef]

28. Kitajima, S.; Shimono, K.; Tajima, J.; Antona-Makoshi, J.; Uchida, N. Multi-agent traffic simulations to estimate the impact of automated technologies on safety. Traffic Inj. Prev. 2019, 20, 58-64. [CrossRef] [PubMed]

29. Tafidis, P.; Pirdavani, A.; Brijs, T.; Farah, H. Can automated vehicles improve cyclist safety in urban areas? Safety 2019, 5, 57. [CrossRef]

30. Ye, L.; Yamamoto, T. Evaluating the impact of connected and autonomous vehicles on traffic safety. Phys. A 2019, 526, 121009. [CrossRef]

31. Yue, L.; Abdel-Aty, M.; Wu, Y.; Wang, L. Assessment of the safety benefits of vehicles' advanced driver assistance. connectivity and low level automation systems. Accid. Anal. Prev. 2018, 117, 55-64. [CrossRef]

32. Kockelman, K.M.; Boyles, S.D.; Avery, P.; Claudel, C.; Loftus-Otway, L.; Fagnant, D.; Bansal, P.; Levis, M.W.; Zhao, Y.; Liu, J.; et al. Bringing Smart Transportation to Texans: Ensuring the Benefits of a Connected and Autonomous Transport System in Texas-Final Report; The University of Texas Austin: Austin, TX, USA, 2016; p. 364.

33. Kockelman, K.M.; Li, T. Valuing the safety benefits of connected and automated vehicle technologies. In Proceedings of the Transportation Research Board 95th Annual Meeting, Washington, DC, USA, 10-14 January 2016.

34. Yang, C.Y.D.; Fisher, D.L. Safety impacts and benefits of connected and automated vehicles: How real are they? J. Intell. Transp. Syst. 2021, 25, 135-138. [CrossRef]

35. Kockelman, K.; Avery, P.; Bansal, P.; Boyles, S.D.; Bujanovic, P.; Choudhary, T.; Clements, L.; Domnenko, G.; Fagnant, D.; Helsel, J.; et al. Implications of Connected and Autonomous Vehicles on the Safety and Operations of Roadway Networks: A Final Report; The University of Texas Austin: Austin, TX, USA, 2016; p. 185.

36. Finlex. Law on Investigations of Road and Off-Road Accidents. Available online: https://www.finlex.fi/fi/laki/ajantasa/2016/2 0161512 (accessed on 27 March 2020).

37. Kelkka, M.; Toivonen, S. Crash Violence of the Transport System (Liikennejärjestelmän Kolariväkivalta); Ministry of Transport and Communications: Helsinki, Finland, 2011.

38. Hancock, P.A.; Nourbakhsh, I.; Stewart, J. On the future of transportation in an era of automated and autonomous vehicles. Proc. Natl. Acad. Sci. USA 2019, 116, 7684-7691. [CrossRef]

39. Yang, W.; Zhang, X.; Lei, Q.; Cheng, X. Research on Longitudinal Active Collision Avoidance of Autonomous Emergency Braking Pedestrian System (AEB-P). Sensors 2019, 19, 4671. [CrossRef]

40. Fernandes, P.; Nunes, U. Platooning With IVC-Enabled Autonomous Vehicles: Strategies to Mitigate Communication Delays, Improve Safety and Traffic Flow. IEEE Trans. Intell. Transp. Syst. 2012, 13, 91-106. [CrossRef] 
41. Utriainen, R.; Pollanen, M.; Liimatainen, H.I. The Safety Potential of Lane Keeping Assistance and Possible Actions to Improve the Potential. IEEE Trans. Intell. Veh. 2020, 5, 556-564. [CrossRef]

42. Kühn, W.; Muller, M.; Höppner, T. Road Data as Prior Knowledge for Highly Automated Driving. Transp. Res. Procedia 2017, 27, 222-229. [CrossRef]

43. Noy, I.Y.; Shinar, D.; Horrey, W. Automated driving: Safety blind spots. Saf. Sci. 2018, 102, 68-78. [CrossRef] 